ISBN 978-81-933894-1-6

2017 International Conference on Studies in Business Management, Law and Education

(SBMLE-17)

Kyoto (Japan) April 20-21, 2017

\title{
The Training Satisfaction of New Life Insurance Sales Agents
}

\author{
Ang Liu ${ }^{1}$, Shih I Yen ${ }^{2}$ \\ ${ }^{1}$ Nanfang College of Sun Yat-Sen University, \#882, Wenquan Ave, Conghua District, Guangzhou City, \\ Guangdong, 510970, China. \\ ${ }^{2}$ Nanfang College of Sun Yat-Sen University, \#882, Wenquan Ave, Conghua District, Guangzhou City, \\ Guangdong, 510970, China.
}

\begin{abstract}
The market of life insurance get more request to the life insurance sale agents in their abilities with the demand expanding continuously in Shenzhen, China. It is more important for the novice at life insurance sale business to get training. Therefore, the aim of this paper is developing the questionnaire with validity and reliability to measure the Nucturing Premier Agent (NPA) training satisfaction at present as well as dividing the 10 abilities which NPA training aimed to improve by Kano model. The importance and satisfaction are also considered as references, Kano model and importance \& satisfaction are combined to evaluate the order of improvement of 10 abilities NPA training concluded. According to the statistic, 8 of 10 abilities of NPA training are one-dimensional quality; 2 of 10 abilities are indifferent quality etc. This study proposed the recommendations on improvement strategies of NPA training.
\end{abstract}

Keywords: Life insurance, Kano model, training, perceived importance, satisfaction

\section{Introduction}

\subsection{General Background Information}

With the economy development of China mainland, residents' consuming potential has been developed on the large scale. At the same time, life insurance market get a skyrocket. At the end of 2014, insurance company in China mainland get year-on-year increasing in $17.49 \%$, Sun $(2016)^{[1]}$. The sales of life insurance are also boosted. In Shenzhen, China, according to the data published by CIRC: since Jan 2015 to Jul, the life insurance premium is $¥ 217$ million, which is boosted about $28.78 \%$ at the same time in 2016 .

The kinds of life insurance get diversified with the increasing of life insurance demands and meanwhile, the abilities of life insurance sales agents are also challenged by new status of life insurance market. So that, the training to those novice life insurance sales agent must be attached more importance.

The A China Premier Academy Training Navigator launched by A Life Insurance Corporation (A Corp.), which is the parents company of A company in Shenzhen, is so famous in life insurance industry that many other life insurance are considering it as reference of training conduction. The Nutructing Premier Agents (NPA) Training, is also conducted according to it. This kind of training aimed to assist those who want to become the life insurance sales agent of A Shenzhen to get necessary abilities. However, there is no systematic and detailed research on trainees' satisfaction conducted so far. Hence, the questions of this research will explore is follow:

Q1: What's the satisfaction of NPA trainees to NPA training?

Q2: What's the preferences of NPA trainees?

And research purposes are:

1. Developing a questionnaire with more reliability and validity. 
2. Exploring the preferences of NPA trainees.

3. Measuring the satisfactions of NPA trainees.

\section{Literature Review}

\subsection{Training}

Training is the critical component of human resources management and organization development. As one of the most famous training effectiveness evaluation of methods----Kirkpatrick Model, raised by Donald. L. Kirkpatrick $^{[2]}$ (1959) considers training effectiveness across 4 levels, which is: Reaction, Learning, Behaviour and results. Shih ${ }^{[3]}$ (2013) considered: The general collection of all necessary knowledges, skills, concepts, qualities, even position regulations related learning, promoting, and acting. Jeng ${ }^{[4]}$ (2005) pointed out that LIMRA considers it is the most important for training of life insurance agents to get KASH training. KASH consists of: Knowledge, Attitude, Skill and habit. Cheng ${ }^{[5]}$ (2002) pointed out that there is a positive relationship between the performances of life insurance sales agents and training effectiveness.

\subsection{Kano Model}

The Kano Model was developed by Noriaki Kano ${ }^{[6]}$ (1984), inspired by Two-Factor Theory (also called: Motivator-Hygiene Theory) from Herzberg ${ }^{[7]}$ (1959). Noriaki Kano divided Kano model into five, it is: Must-be quality element, One-dimension quality element, Attractive quality element, indifferent quality element and Reverse quality element. Charles Berger ${ }^{[8]}$ (1993) improved Kano model by launching the concept of Customer Satisfaction Coefficient (CS), which is consist of Satisfaction Index (SI) and Dissatisfaction Index (DI).

The order of Kano model 4 kinds of qualities (except reverse quality) is: $\mathrm{M}>\mathrm{O}>\mathrm{A}>\mathrm{I}$.

\subsection{Importance-Performance Analysis, IPA}

The Importance-Performance Analysis, which is short for IPA, was raised by Martilla \& James ${ }^{[9]}$ (1977). The results of IPA analysis can be put into a two dimensions matrix. The x-axis stands for importance and the yaxis stands for performance. The explanation of four quadrants separately are as follow:

- Quadrant 1: High importance/high performance.

- Quadrant 2: Low importance/high performance.

- Quadrant 3: Low importance/ low performance.

- Quadrant 4: High importance/ low performance.

\section{Method}

The study is to investigate life insurance sales agents and the investigation is conducted in A company, Shenzhen, China. An interview with Ms. A, who has been worked in A company for over 8 years as a lecturer of training department of A Shenzhen was conducted before designing questionnaires in order to know the classification of contents of NPA training and situation of NPA training. According to the results of interview and combining Kano model as well as IPA, the questionnaires are developed and distributed, which is:

- Satisfaction \& importance questionnaire, also is IPA questionnaire

- Training preference questionnaire, also is Kano model questionnaire

Both of two questionnaires are operated according to Likert scales so that measuring the classification, importance and satisfaction of 10 abilities of NPA training. Training preference questionnaire was sent 131 copies out and 131 copies retrieved with 91 effective and 40 copies ineffective. Satisfaction \& importance questionnaire was sent 131 copies out and 131 copies retrieved with 131 effective and 0 copies ineffective.

\subsection{Study 1: Interview}

This interview is about follow questions:

1. What's the accordance of NPA contents?

2. How is the effectiveness of NPA evaluated?

3. What's the results of effectiveness of NPA?

The result of interview as follow:

1. The contents of NPA training are designed according to KASH rules raise by LIMRA. It is mainly aimed to improve 10 abilities of trainee, their classifications are as follow 
Table 1. The Classification of 10 Abilities NPA Training Contents

\begin{tabular}{|c|c|}
\hline Classification & Contents \\
\hline Knowledge (K) & $\begin{array}{c}\text { Knowledge on insurance(K1), Demand analysis and } \\
\text { combination of products (K2), Sale certification (K3) }\end{array}$ \\
\hline Attitude (A) & Attitude to career and self-management (A1) \\
\hline Skill (S) & $\begin{array}{c}\text { Sale recycle (S1), Presentation of products (S2), Service } \\
\text { and claim procedure (S3), Present proposal (S4), Junior } \\
\text { recruiting skills (S5) }\end{array}$ \\
\hline Habit (H) & Application of APP (H1). \\
\hline
\end{tabular}

2. At present, the evaluation of NPA training are conducted by distributing questionnaire to trainees at the end of training, but lack of reliability. This situation is based on 2 reasons. First, Trainees don't want to show their dissatisfactions in the questionnaires because they think this kind of training ought to attend for only once. Second, Trainees worry about their relationship with colleagues may be negatively influenced after the negative evaluations are known by lecturer or other colleagues.

\subsection{Study 2: Questionnaire}

This study developed two questionnaires, which are satisfaction \& importance questionnaire and training preference questionnaire.

\subsubsection{Satisfaction \& Importance Questionnaire}

This questionnaire developed by Shi (2012) is followed in this research. The dimension of questionnaire are replaced by KASH and questions are replaced by 10 abilities NPA contents. The point of each option stands for is 1 to 5 in order. The higher the point is, the higher satisfaction/importance is, vice versa.

\subsubsection{Training Preference Questionnaire}

There are 20 questions in total, NPA's 10 abilities in each question will be asked about each abilities both directly and reversely, twice in total. The classification results of each abilities depends on the combination of options of direct question and reverse question. It is as follow:

Table 2. The Classification of Quality and Meaning of Options of Questionnaire

\begin{tabular}{|c|c|c|c|c|c|}
\hline Negative & $\begin{array}{l}\text { I like it that } \\
\text { way }\end{array}$ & $\begin{array}{c}\text { It must be that } \\
\text { way }\end{array}$ & I am neutral & $\begin{array}{l}\text { I can live with } \\
\text { it that way }\end{array}$ & $\begin{array}{l}\text { I dislike it that } \\
\text { way }\end{array}$ \\
\hline $\begin{array}{l}\text { I like it that } \\
\text { way }\end{array}$ & Q & A & A & A & $\mathrm{O}$ \\
\hline $\begin{array}{l}\text { It must be that } \\
\text { way }\end{array}$ & $\mathrm{R}$ & I & I & I & $\mathrm{M}$ \\
\hline I am neutral & $\mathrm{R}$ & $\mathrm{I}$ & I & I & M \\
\hline $\begin{array}{l}\text { I can live with } \\
\text { it that way }\end{array}$ & $\mathrm{R}$ & I & I & I & $\mathrm{M}$ \\
\hline $\begin{array}{l}\text { I dislike it that } \\
\text { way }\end{array}$ & $\mathrm{R}$ & $\mathrm{R}$ & $\mathrm{R}$ & $\mathrm{R}$ & Q \\
\hline
\end{tabular}

The options and their meanings are based on opinion of Matzler \& Hinterhuber (1998) with little adjustments. The options and meanings are as follow:

Table 3. The Meaning of Options

\begin{tabular}{|c|c|}
\hline $\begin{array}{c}\text { I like it that } \\
\text { way }\end{array}$ & You are satisfied when this training is helpful for your corresponding ability \\
\hline $\begin{array}{c}\text { It must be that } \\
\text { way }\end{array}$ & This training must helpful for me to improve related ability \\
\hline I am neutral & The assistance of improving my ability from this training don't reach my expectation, but \\
that's ok.
\end{tabular}


After finish classification of each abilities, the DI, SI as well as averaged satisfaction value of eachquestions will be calculated.

\subsubsection{Reliability \& Validity Analysis}

The Cronbach $\alpha$ value of Study 1 is above 0.73 , which is acceptable, and the content validity is also convinced acceptable by researchers. The Cronbach $\alpha$ value of satisfaction $\&$ importance questionnaire is 0.93 , and the criterion-related validity is 0.96 . The Cronbach $\alpha$ value of training preference questionnaire is 0.72 , and the criterion-related validity is 0.85. The measuring method is from John O. Summers and David B. MacKay (1976) ${ }^{[10]}$

\subsubsection{Kano Model and IPA Cross-Analysis}

The SI and DI value will be reached according to the results of Training preference questionnaire (Kano model questionnaire), combined with IPA, then get present satisfaction of NPA training, trainee's preference and the order of improvement each abilities.

\section{Result}

\subsection{IPA(Importance-Performance Analysis)}

The Likert scale is applied to measure the satisfaction and importance of 10 abilities which NPA training aimed to improve. The averages of satisfaction and orders of each abilities are as follow:

Table 4. The Average of Satisfaction

\begin{tabular}{|l|l|c|}
\hline Order & Abilities NPA training including & Average satisfaction \\
\hline 1 & (A1) Attitude to career and self-management & 4.25 \\
\hline 2 & (S1) Sale recycle & 4.22 \\
\hline 3 & (S2) Presentation of products & 4.15 \\
\hline 4 & (K1) Basic knowledge on insurance & 4.14 \\
\hline 5 & (S3) Service and claim procedure & 4.09 \\
\hline 6 & (K2) Demand analysis and combination of products \\
\hline 7 & (H1) Application of APP & 3.01 \\
\hline 8 & (K3) Sale certification & 3.95 \\
\hline 9 & (S4) Present proposal & 3.94 \\
\hline 10 & (S5) Junior recruiting skills & 3.90 \\
\hline
\end{tabular}

The (A1) Attitude to career and self-management get the highest score which is 4.25 and (S5) Junior recruiting skills get lowest scores which is 3.90 .

Table 5. The averages of importance

\begin{tabular}{|l|l|r|}
\hline Order & Abilities NPA training including & Average importance \\
\hline 1 & (S3) Service and claim procedure & 4.5 \\
\hline 1 & (S5) Junior recruiting skills & 4.5 \\
\hline 2 & (K1) Basic knowledge on insurance & 4.47 \\
\hline 3 & (A1) Attitude to career and self-management & 4.46 \\
\hline 4 & (S4) Present proposal & 4.44 \\
\hline 5 & (K2) Demand analysis and combination of products & 4.42 \\
\hline 6 & (S2) Presentation of products & 4.41 \\
\hline 7 & (S1) Sale recycle & 4.36 \\
\hline 7 & (K3) Sale certification & 4.36 \\
\hline 8 & (H1) Application of APP & 4.22 \\
\hline
\end{tabular}

The (S3) as well as (S5) both get the best score which is 4.5 and (H1) get the lowest scores which is 4.22. 


\subsection{Kano Model Analysis}

Table 6. The Classification of 10 Abilities of NPA By Kano Model

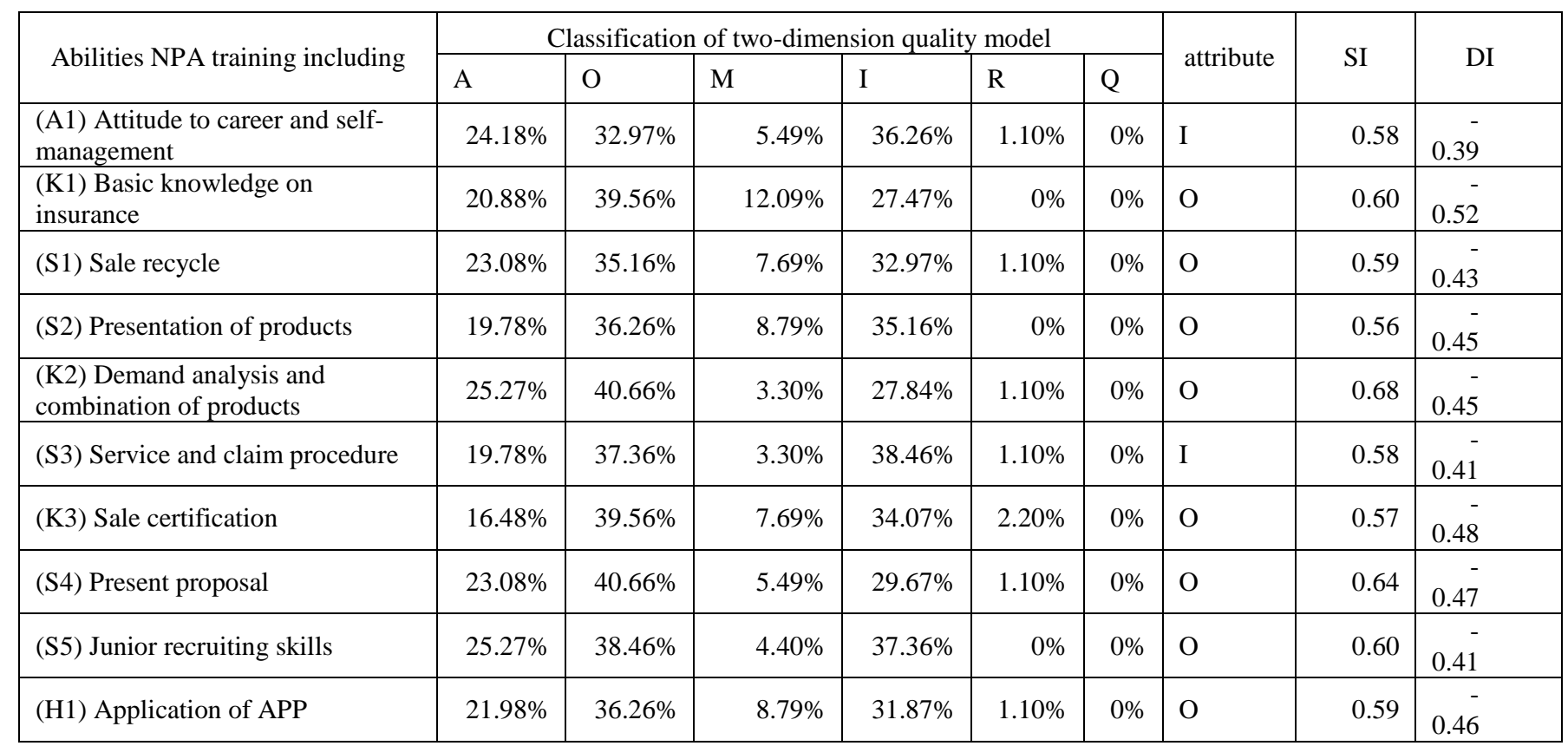

The statement about classification of 10 abilities which NPA training include is as follow:

. One-dimensional quality consist of: (K1), (S1), (S2), (K2), (K3), (S4), (S5), (H1).

- Indifferent quality include: (A1) and (S3) Service and claim procedure.

- All absolute values of SI are larger than absolute value of DI. The maximum absolute value of SI is 0.56; the minimum absolute value of DI is 0.52 .

\subsection{IPA \& Kano Model Cross-Analysis} follow:

The satisfaction and importance of 10 abilities NPA training including in A Shenzhen can be presented as

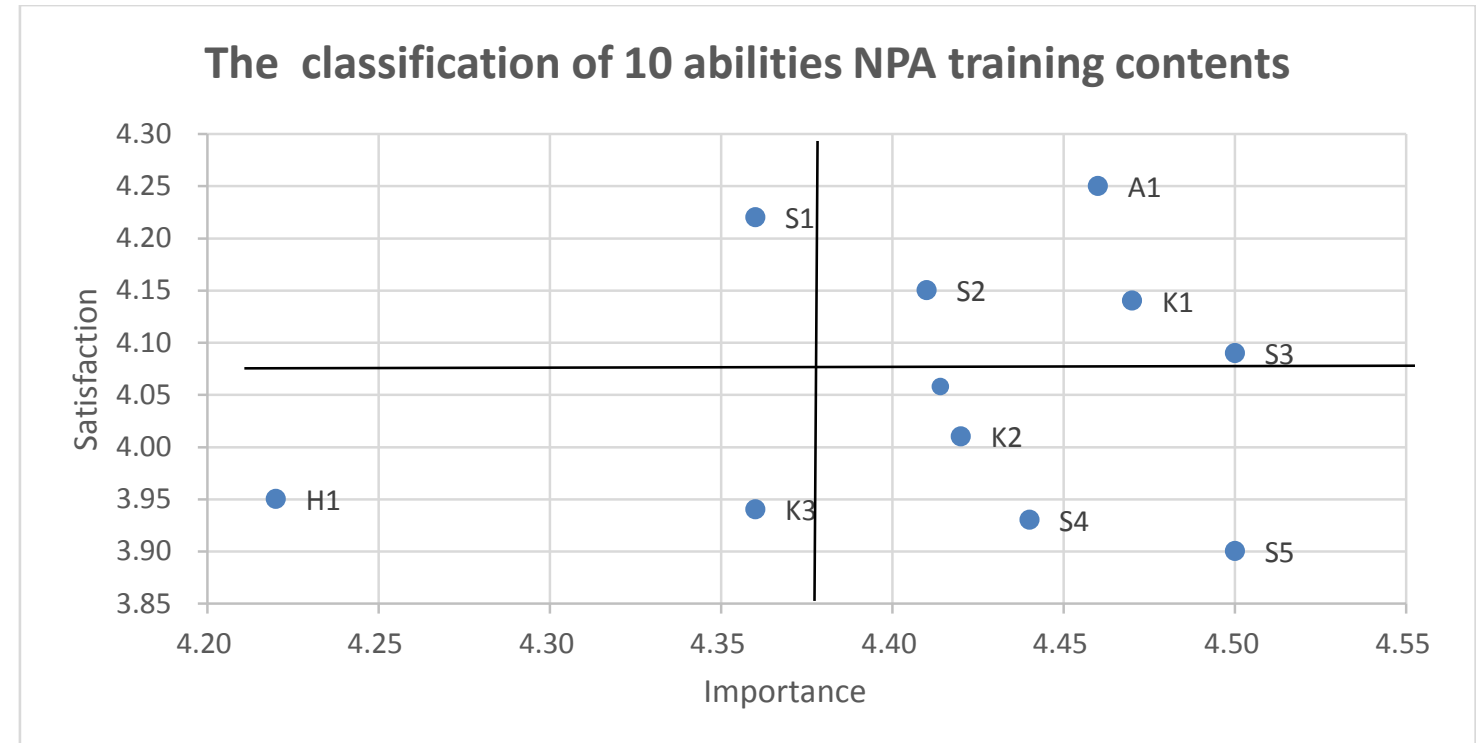

Fig. 1: The Classification of 10 Abilities NPA Training Contents 
The explanations are as follow:

- The points in quadrant 1 are: (A1), (K1), (S2), (S3). These abilities in NPA training should keep present situation for their high importance and high performance.

- The point in quadrant 2 is: (S1). The resources distributed to this ability in NPA training maybe excessive. It is highly recommended to reduce resources put into for low importance and high performance.

- The points in quadrant 3 are: (K1) and (K3). If the importance of them in NPA training don't change in short term, they can be considered as secondary improvement options for low importance and low performance.

- The point in quadrant 4 are: (K2), (S4), (S5). These abilities should be improved as soon as possible for high importance and low performance.

\section{Summery and Conclusions}

\subsection{Conclusions}

The questionnaires developed in this study can measure preferences and satisfactions of NPA training more precisely than before. In other words, it shows the necessary abilities and skills for life insurance sales agent' work. And it also presents the importance of each abilities for trainees. The order of abilities included by NPA from most important to less important is: Junior recruiting skills (S5), Present proposal (S4), Demand analysis and combination of products (K2), Sale certification (K3), Application of APP (H1), Sale recycle (S1), Basic knowledge on insurance (K1), Presentation of products (S2), Service and claim (S3), Attitude to career and selfmanagement (A1).

\subsection{Suggestions}

The results of this research presents that the contents of NPA are mainly consist of skill training. The training to novices of insurance sales agents ought to focus more on skills and attitude aspects. It is a prerequisite for novices of life insurance sales agents getting a bright future in insurance industry to keep a proper attitude to their career.

\section{Acknowledgements}

The author gratefully acknowledges Ms. A and other colleagues for their fully cooperated. With their efforts in data collection and support on information, this research can be finished successfully.

\section{References}

[1] Q.X. Sun, 2016, China Insurance Market Report

[2] Kirkpatrick, D.L., "Techniques for evaluating training program”, Training and Development Journal. 1959.

[3] S.M. Shih, "The study on Applying Kano and IPA to evaluate online learning platform improvements -A case study in electro optical industry education and training", M.S. thesis, Dept. innovation and Technology management, national Chin- Yi of technology Univ., Taiwan, 2012.

[4] Yoau-Chau Jeng, "Establishment of Evaluation Indicators for Students Practical Training in Insurance Industry", Chaoyang University of technology.

[5] C.K. Cheng, "The correlation between performances of life insurance sale agents and effectiveness of training", M.S. thesis, Dept. Risk Management \& Insurance, Kaohsiung first technology Univ., Taiwan, 2002.

[6] Kano Noriaki, Nobuhiku Sereku etc. "Attractive quality and must-be quality". Journal of the Japanese Society for Quality Control, 1984.

[7] Herzberg, Frederick; Mausner, Bernard; Snyderman, Barbara B. (1959). The Motivation to Work (2nd ed.). New York: John Wiley. ISBN 0471373893.

[8] Charles Berger etc., “Kano's method for understanding customer-defined quality”, The Center for Quality Management Journal, 1993.

[9] Martilla \& James, Importance-Performance Analysis, Journal of Marketing. Jan., 1977

[10] John O. Summers and David B. MacKay, Journal of Marketing Research Vol. 13, No. 3, pp. 289-295], (Aug., 1976). 